\title{
dspace.vutbr.cz
}

\section{Comparison of Simple Design Methods for Voltage Controllable Resistance}

ŠOTNER, R.; DOMANSKÝ, O.; LANGHAMMER, L.; PETRŽELA, J.

Proceedings of 30th International Conference Radioelektronika (RADIOELEKTRONIKA 2020), pp. 1-6

elSBN: 978-1-7281-6469-4

DOI: https://doi.org/10.1109/RADIOELEKTRONIKA49387.2020.9092366

Accepted manuscript

C2020 IEEE. Personal use of this material is permitted. Permission from IEEE must be obtained for all other uses, in any current or future media, including reprinting/republishing this material for advertising or promotional purposes, creating new collective works, for resale or redistribution to servers or lists, or reuse of any copyrighted component of this work in other works. ŠOTNER, R.; DOMANSKÝ, O.; LANGHAMMER, L.; PETRŽELA, J., "Comparison of Simple Design Methods for Voltage Controllable Resistance", Proceedings of 30th International Conference Radioelektronika (RADIOELEKTRONIKA 2020), pp. 1-6, 2020. DOI: 10.1109/RADIOELEKTRONIKA49387.2020.9092366. Final version is available at https://ieeexplore.ieee.org/document/9092366 


\title{
Comparison of Simple Design Methods for Voltage Controllable Resistance
}

\author{
Roman Sotner, Ondrej Domansky, Lukas Langhammer, Jiri Petrzela \\ SIX Research Center, Department of Radio Electronics \\ Brno University of Technology \\ Brno, Czech Republic \\ sotner@feec.vutbr.cz
}

\begin{abstract}
This paper compares several ways of electronic resistance control for tunable applications (filters, oscillators, amplifiers, etc.). Simulation (PSpice) and experimental tests of basic J-FET transistor-based adjustable resistor, optocoupler as well as more advanced active solutions using active devices (variable gain amplifiers, voltage-mode multiplier) are performed in order to see available linear range, readjustability range and expected frequency features.
\end{abstract}

Keywords-Electronic control, J-FET, resistor, variable gain amplifier, voltage driving

\section{INTRODUCTION}

Integrated circuit design [1] offers very easy way of adjustability in applications depending on resistor value(s). Especially very simple construction of operational transconductance amplifier (OTA) [2]-[4] and its simple application for resistor emulation [2] represents the main benefit of this way. However, standard constructers and designers have quite limited possibilities. There are several ways including also discontinuously settable digital potentiometers [5], [6] or digital to audio converters [7]. Unfortunately, many analog and mixed applications and systems require continuous adjustability of resistance value where these solutions are not suitable. The continuous control of resistance value, solved by analog way, has certain limitations. The highest issues are linearity of voltage dependence across the element on current and frequency bandwidth limitation. Standard component base, available for designers, offers several types of J-FET and MOSFET transistors [8], that can be used for resistor replacement (operating in linear/triode regime [1], [8]) but also some special types of electronically adjustable active elements can be selected as better option for indicated features (resistivity control in circuit application with operational amplifiers for example).

The following text compares several typical and also unusual ways of electronic control of resistance and compares their linearity, range of applied current and voltage across the element, frequency bandwidth and range of available resistance value.

\section{EASILy Available Methods of Resistance CONTROL}

\section{A. Single J-FET transistor}

The simplest method of replacement of resistor by electronically adjustable equivalent supposes usability of MOSFET transistor [1], [8] in triode/linear (ohmic regime). The method is very simple and straightforward but result has several important drawbacks and limitations discussed in experimental part. The basic circuits using depletion Junction

Research described in the paper was supported by Czech Science Foundation project under No. 19-22248S. For the research, infrastructure of the SIX Center was used.
FET (J-FET) [8] of $\mathrm{N}$ channel polarity are shown in Fig. 1. The driving voltage $V_{\text {set }}$ has negative polarity for this type of transistor. Large signal analysis of circuit in Fig. 1(a) determines equivalent resistance of JFET in form ( $V_{\mathrm{GS}(\mathrm{off})}$ is threshold voltage and $I_{\text {DSS }}$ is maximal drain short channel current for zero bias):

$$
R_{\text {eq_large }}=\frac{V_{G S(o f f)}}{I_{D S S}\left[\left(V_{G S}-V_{G S(o f f)}\right)-\frac{V_{D S}}{2}\right]} .
$$

Small-signal resistance (for $V_{\mathrm{DS}}<V_{\mathrm{GS}}-V_{\mathrm{TH}}$ ) is defined as:

$$
R_{\text {eq_small }}=\frac{V_{G S(o f f)}}{I_{D S S}\left(V_{G S}-V_{G S(o f f)}\right)},
$$

unfortunately, nonlinearity of this solution for larger $V_{\mathrm{DS}}$ voltages is high (usability up to tens of $\mathrm{mV}$ and low tenshundreds of $\mu \mathrm{A}$ ), therefore Senani et al. [9], [10] presented improved version using resistor divider in Fig. 1(b) (having equal resistances) in order to reduce influence of $V_{\mathrm{DS}}$ in (1). This modification has form:

$$
\left.R_{e q} \cong \frac{V_{G S(o f f)}^{2}}{I_{D S S}\left(V_{\text {set }}-2 V_{G S(o f f)}\right)}\right|_{R_{a}=R_{b}=R} .
$$

The values of $R_{\mathrm{a}, \mathrm{b}}$ should be several times $(100 \mathrm{k} \Omega)$ larger than expected channel resistance $R_{\text {eq. }}$. However, the range of resistance adjustability is very narrow.

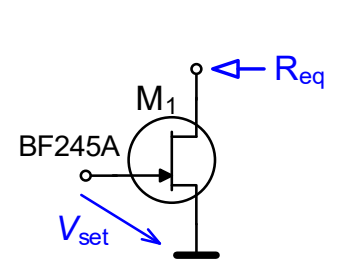

(a)

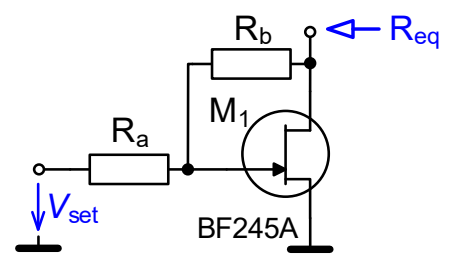

(b)
Fig. 1. J-FET(N) grounded resistors: a) basic concept, b) modified concept.

\section{B. Optocoupler}

Optocouplers, having resistive output port, were very popular in recent works as parts for adjustability and tunability of oscillation frequency and oscillation condition in several types of modern oscillators [11]-[14]. However, types (3WK16341) used in [11]-[14] are quite obsolete and unavailable. The modern type of the optocoupler NSL-32SR3 [15] in Fig. 2 represents quite new device very useful for many applications [16]. These resistive equivalents have quite slow reaction on driving voltage (units of $\mathrm{ms}$ ) but it is not important issue in adjustable applications (condition for oscillation control [11]-[14]). The resulting form for equivalent resistance is: 


$$
R_{O C} \cong 0.2 \cdot\left(\frac{R_{m}}{V_{O C}-V_{t h}}\right) \cong 0.2 \cdot\left(\frac{R_{m}}{V_{O C}-1.6}\right) \text {. }
$$

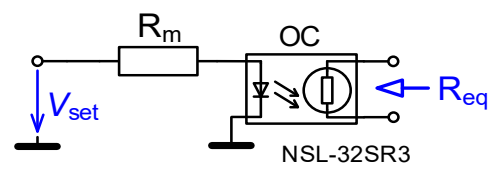

Fig. 2. Optocoupler with resistive output used as floating resistance equivalent.

\section{Variable Gain Amplifier}

The variable gain amplifier (VGA) [3] in the function of equivalent adjustable resistance offers very useful way and also good linearity. The basic operation supposes resistor connected in the feedback and the variable gain serves for control of overall resistance in the input node (Fig. 3). The resulting equation for overall resistance has form:

$$
R_{e q} \cong \frac{R_{e x t}}{(1+A)},
$$

for solution in Fig. 3(a) and

$$
R_{e q}=R_{e x t}(1+A)
$$

for solution in Fig. 3(b). The application of VGA in the resistance equivalent offers simple possibility for negative resistance emulation $(\mp \leftrightarrow \pm)$. Unfortunately, instability issues must be solved in the case of negative resistance quite frequently. This solution was used in recent works very effectively [17]-[19]. There are devices that allow linear driving of gain $A$ (VCA822 [20], VCA824 [21]). Exponential driving of voltage gain $A\left(A=10^{2(\mathrm{Vset}-1)}\right)$ offers very large range of resistance control in some types of VGA (VCA810 [22] for example).

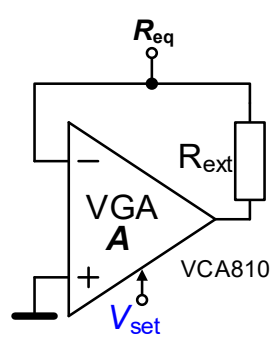

(a)

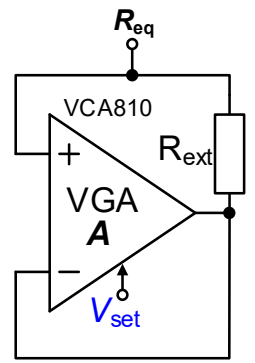

(b)
Fig. 3. Grounded equivalent resistance based on variable gain amplifier: a) single feedback, b) two feedbacks.

The voltage-mode multipliers (AD835 [23] for example) also offer very interesting feature for linearly tunable resistance. Typical concept of the controllable resistance is shown in Fig. 4 and has practically identical topology as previous solution using VCA. Therefore, also definition and equation for equivalent resistance has identical form as (5). Again, polarity of $R_{\text {ext }}$ connection is not important because of simple change by driving voltage $\pm V_{\text {set. }}$

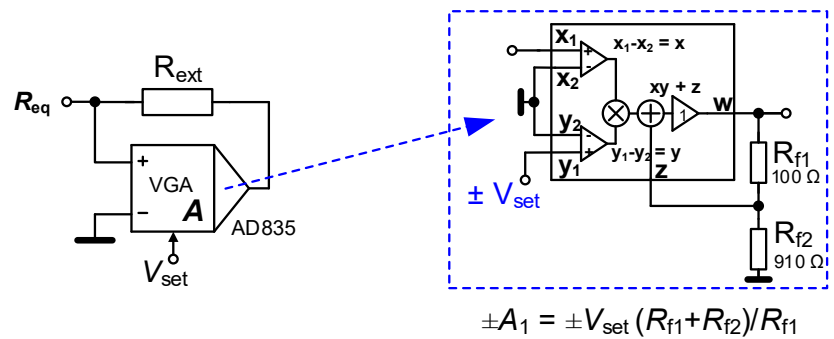

Fig. 4. Grounded equivalent resistance based on variable gain amplifier using voltage-mode multiplier.

\section{ANALYSIS OF PRESENTED SOLUTIONS}

Solutions of discussed adjustable resistance circuits are analyzed by computer simulations (PSpice) and experimentally (optocoupler NSL-32SR3 has no model).

\section{A. Simulation of J-FET in linear regime}

The simplest method of electronic resistance adjustability, shown in Fig. 1(b), was simulated for BF245A J-FET element [24] using both identical resistors $R_{\mathrm{a}}=R_{\mathrm{b}}=R=100 \mathrm{k} \Omega$. and parameters $V_{\mathrm{GS}(\text { off })}=-1.8 \mathrm{~V}, I_{\mathrm{DSS}}=4 \mathrm{~mA}$. The DC driving voltage $V_{\text {set }}$ was changed between -1.79 and $-0.1 \mathrm{~V}$ while resistance varied from 560 up to $211 \Omega$ (theory $450 \rightarrow 231 \Omega$ ). The analysis in Fig. 5 indicates DC behavior and limits of linearity (up to $\pm 1.8 \mathrm{~mA}$ for maximum $560 \Omega$ ). Frequency features of the impedance are analyzed in Fig. 6 (good performance up to $10 \mathrm{MHz}$ approximately - flat response). The dependence of resistance on driving parameter $\left(R_{\mathrm{eq}}\right.$ vS $\left.V_{\text {set }}\right)$ is indicated in Fig. 7.

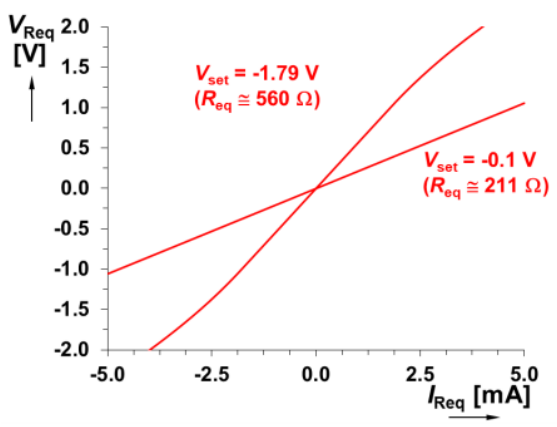

(a)

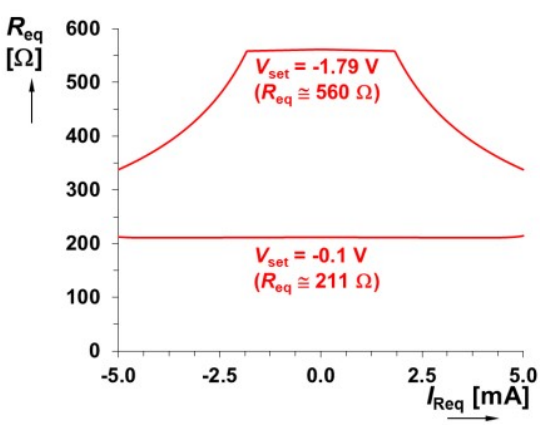

(b)

Fig. 5. J-FET-based resistor analysis: a) voltage across element vs current trougth element, $b$ ) resistance in dependence on current trougth element. 


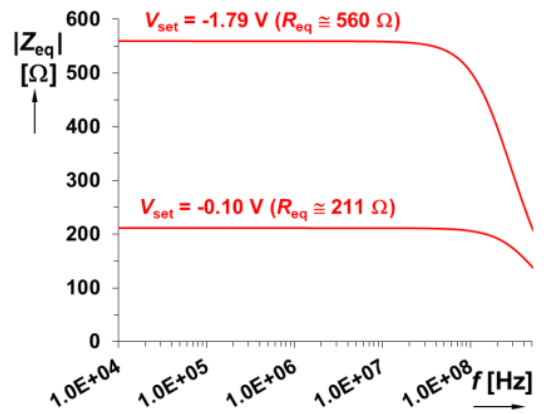

Fig. 6. Frequency responses of impedance magnitude (J-FET).

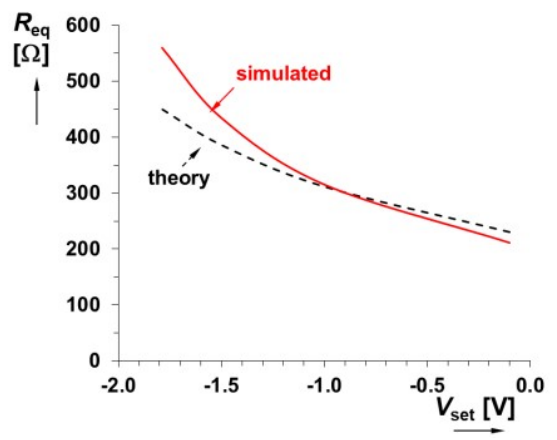

Fig. 7. J-FET Dependence of resistance on driving voltage (J-FET)

\section{B. Measurement of optocoupler}

The device NSL-32SR3 [15] in Fig. 2 was experimentally tested for parameters: $R_{\mathrm{m}}=2.2 \mathrm{k} \Omega, V_{\text {set }}=1.62 \rightarrow 5 \mathrm{~V}$. The $R_{\mathrm{eq}}$ varied between $15 \mathrm{k} \Omega$ and $160 \Omega(22 \mathrm{k} \Omega \rightarrow 127 \Omega$ theoretically). Resulting behavior in DC domain indicates excellent performance in dynamics and linearity (Fig. 8) in wide range (more than $\pm 30 \mathrm{~mA}$ ) for $R_{\mathrm{eq}}=160 \Omega$. Flatness of impedance magnitude frequency responses (Fig. 9) is observable up to $500 \mathrm{kHz}\left(R_{\text {eq }}=15 \mathrm{k} \Omega\right)$. Figure 10 shows the dependence of $R_{\mathrm{eq}}$ on $V_{\text {set. }}$.

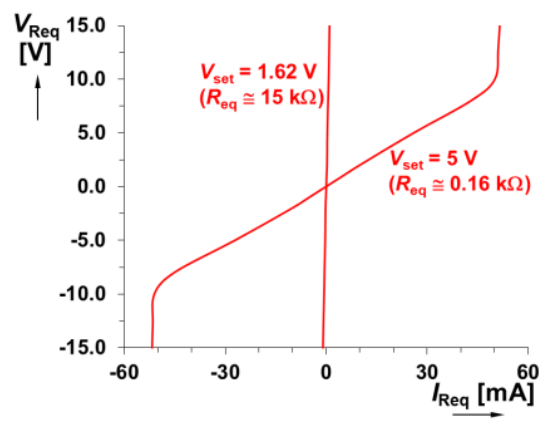

Fig. 8. Voltage across the optocoupler element vs current through element.

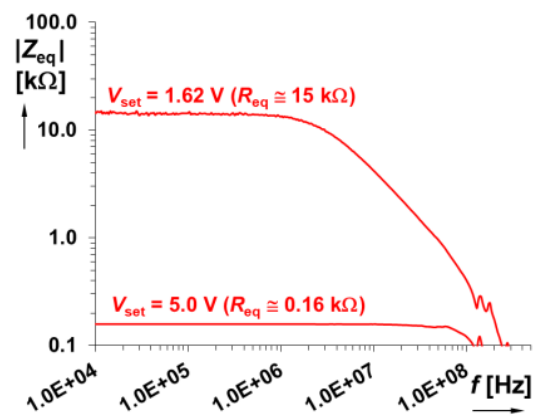

Fig. 9. Frequency responses of impedance magnitude (optocoupler).

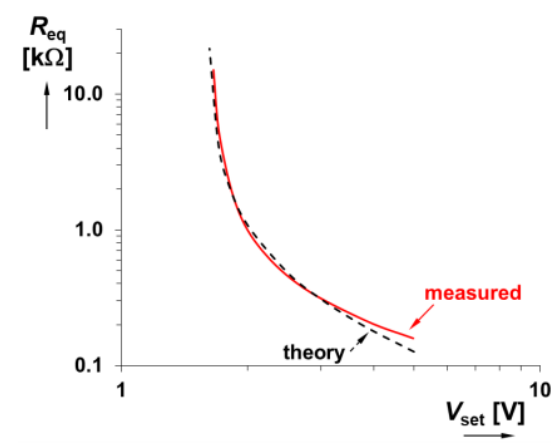

Fig. 10. Dependence of resistance on driving voltage (optocoupler).

\section{Simulation of Variable Gain Amplifier Based Resistance}

Tests of VGA using VCA810 [22] in adjustable resistor (Fig. 3(a)) bring results valid for $R_{\text {ext }}=100 \Omega$ and variation of $V_{\text {set }}=-0.5 \rightarrow-1.5 \mathrm{~V}$. Dynamics with good linearity restricts into the range $\pm 10 \mathrm{~mA}$ (Fig. 11) with flat magnitude up to $10 \mathrm{MHz}$ (Fig. 12) and adjustability of resistance $R_{\text {eq }}$ in Fig. 13 between 98 and $9.2 \Omega(91 \rightarrow 9.1 \Omega$ theoretically).

The second version of the circuit in Fig. 3(b) allows narrower range of good linearity (Fig. 14) than solution in Fig. 3(a), approximately only $\pm 1 \mathrm{~mA}$ for $R_{\mathrm{eq}}=1.2 \mathrm{k} \Omega\left(V_{\text {set }}=-\right.$ $1.5 \mathrm{~V})$. Frequency features show flat magnitude up to $3 \mathrm{MHz}$ (Fig. 15). Adjustability of $R_{\text {eq }}$ was tested between 0.12 and $1.2 \mathrm{k} \Omega(0.11 \rightarrow 1.1 \mathrm{k} \Omega$ theoretically), see Fig. 16 .

Two previous solutions used exponentially adjustable gain. However, the linear driving of gain can be also interesting. The typical modern device known as voltagemode multiplier AD835 [23] was selected for these purposes (Fig. 4). The value of $R_{\text {ext }}=100 \Omega$ was applied also in this case but driving voltage $V_{\text {set }}$ was adjusted from 0.1 up to $1 \mathrm{~V}$. Figure 17 illustrates better width of linearity than previous case $( \pm 5 \mathrm{~mA})$ for very similar range of $R_{\mathrm{eq}}$ between 0.19 and $0.9 \mathrm{k} \Omega(0.2 \rightarrow 1.1 \mathrm{k} \Omega$ in theory). Frequency features in Fig. 18 show constant $R_{\text {eq }}$ value up to $200 \mathrm{kHz}$. Dependence of $R_{\mathrm{eq}}$ on $V_{\text {set }}$ is given in Fig. 19.

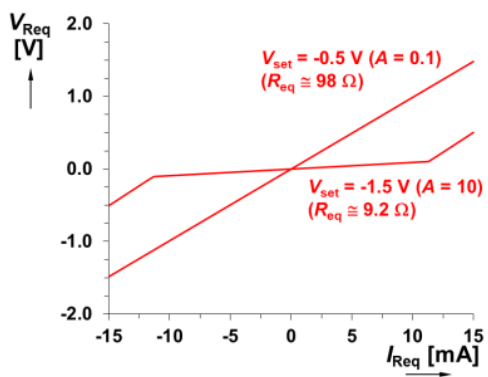

(a)

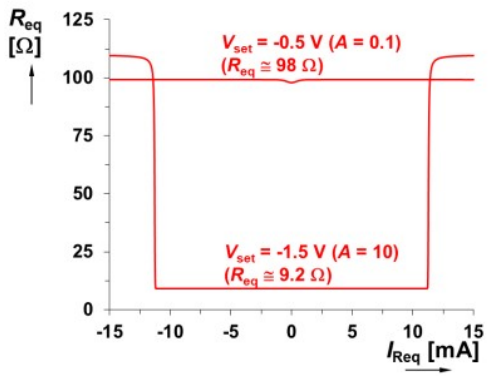

(b)

Fig. 11. The first VGA-based resistor analysis : a) voltage across element vs current trougth element, b) resistance in dependence on current trougth element. 


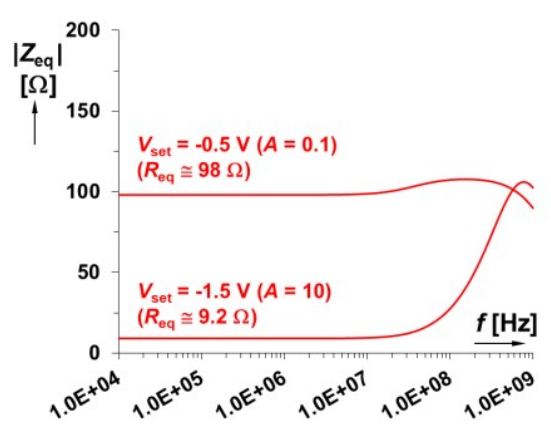

Fig. 12. Frequency responses of impedance magnitude (first VGA-based resistor).

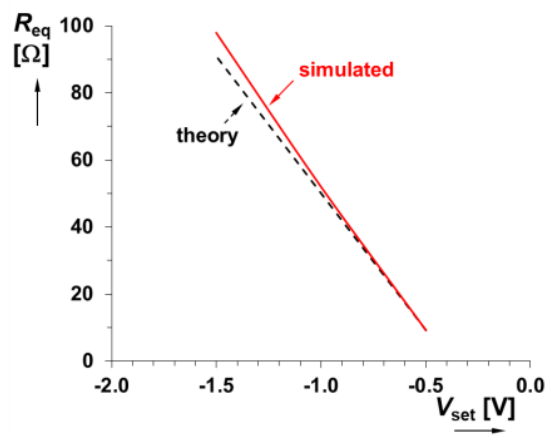

Fig. 13. Dependence of resistance on driving voltage (first VGA-based resistor).

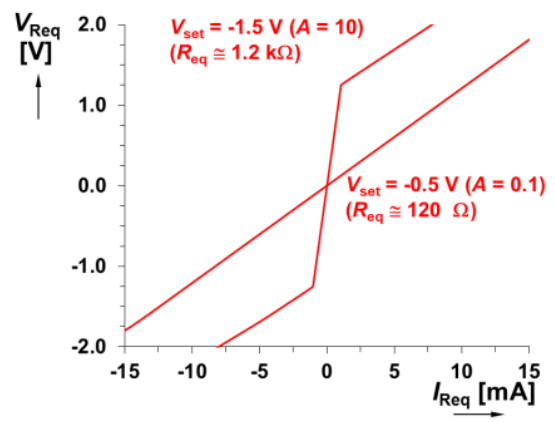

(a)

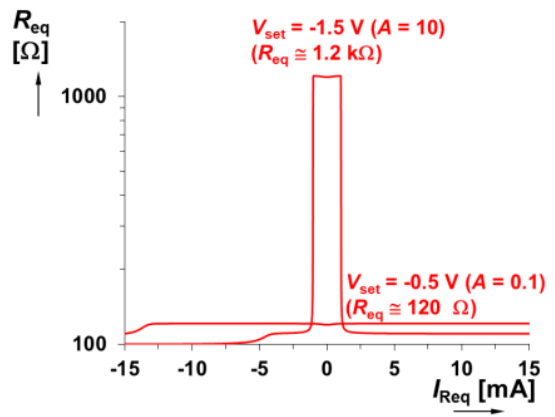

(b)

Fig. 14. The second VGA-based resistor analysis : a) voltage across element vs current trougth element, b) resistance in dependence on current trougth element

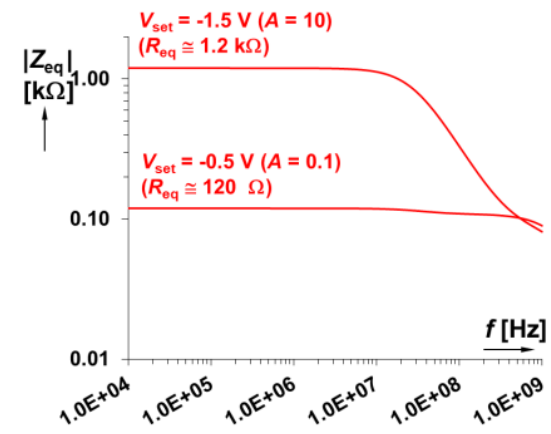

Fig. 15. Frequency responses of impedance magnitude (second VGA-based resistor).

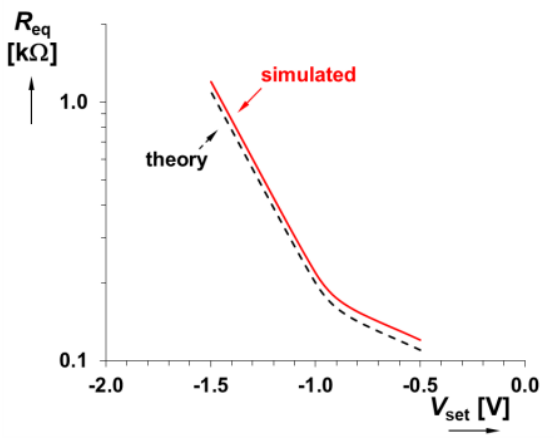

Fig. 16. Dependence of resistance on driving voltage (second VGA-based resistor).

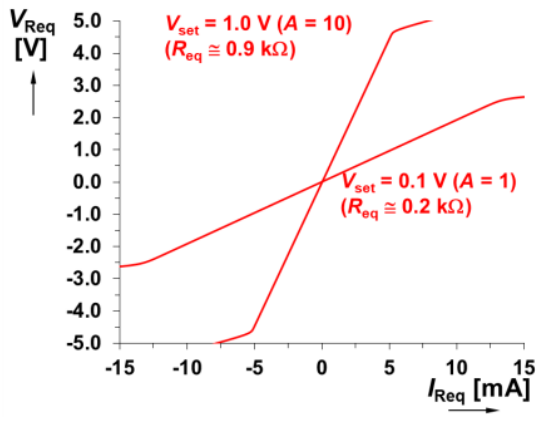

(a)

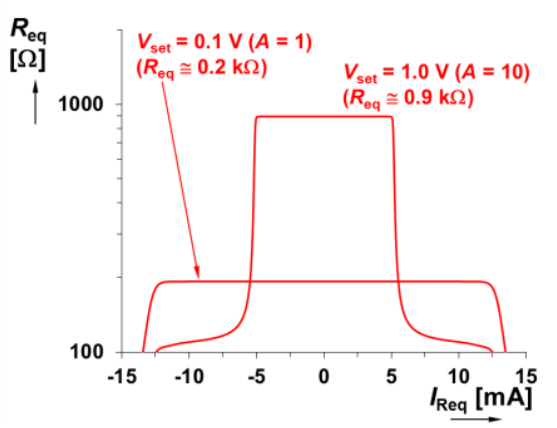

(b)

Fig. 17. Voltage-mode multiplier-based resistor analysis : a) voltage across element vs current trougth element, b) resistance in dependence on current trougth element. 


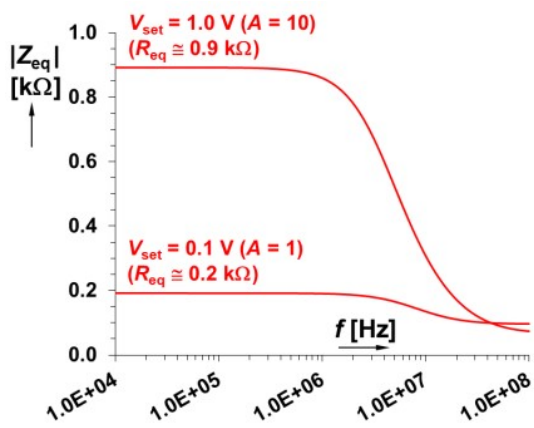

Fig. 18. Frequency responses of impedance magnitude (voltage-mode multiplier-based resistor).

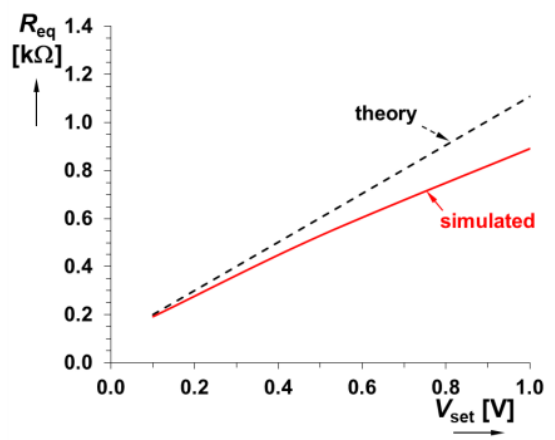

Fig. 19. Dependence of resistance on driving voltage (voltage-mode multiplier-based resistor).

TABLE I. COMPARISON OF STUDIED SOLUTIONS

\begin{tabular}{|c|c|c|c|c|c|}
\hline 总 & 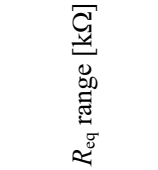 & 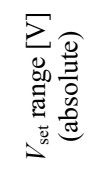 & 愨 & 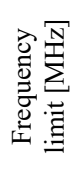 & 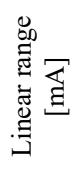 \\
\hline Fig. 1(b) & $0.21 \rightarrow 0.56$ & $0.1 \rightarrow 1.8$ & 0.15 & 10 & \pm 1.8 \\
\hline Fig. 2 & $15 \rightarrow 0.16$ & $1.62 \rightarrow 5$ & 30 & 0.5 & \pm 30 \\
\hline Fig. 3(a) & $0.098 \rightarrow 0.009$ & $0.5 \rightarrow 1.5$ & 3.6 & 10 & \pm 10 \\
\hline Fig. 3(b) & $0.12 \rightarrow 1.2$ & $0.5 \rightarrow 1.5$ & 3.3 & 3 & \pm 1 \\
\hline Fig. 4 & $0.19 \rightarrow 0.9$ & $0.1 \rightarrow 1$ & 0.5 & 0.2 & \pm 5 \\
\hline
\end{tabular}

\section{COMParison OF STUdied SOlutions}

All tested types were designed with very similar or identical values of external $R_{\text {ext }}$ component (when applicable) in order to ensure very similar conditions for all tests. Table 1 shows comparison of studied solutions from several points of view $\left(R_{\text {eq }}\right.$ range, ratio of readjustability in dependence on applied driving voltage, frequency limitation, and linearity restriction). The conclusions are following. As expected, the J-FET has the narrowest range of $R_{\mathrm{eq}}$ control and linearity. Due to the simplicity, the frequency features should be good (about $10 \mathrm{MHz}$ ). Both VGA-based equivalent resistors have quite good ratio of readjustability. However, the linear dynamics of the second type (Fig. 3(b)) is very similar to JFET (Fig. 1(b)) type (the worst one from the studied cases). The best dynamical performances were obtained for optocoupler in Fig. 2 (wide dynamical range of good linearity and readjustability ratio), however, frequency features are almost the worst from studied cases. The optocoupler represents very useful solution for circuit structures using many floating passive resistors. Perfect examples of application are frequency filter [25], oscillator [16].

\section{CONCLUSION}

Presented results show important findings. Standard MOSFET or J-FET transistors are suitable only for very simple applications where quite narrow range of resistance (even for linearized solution) and quite low signal level $(<$ $500 \mathrm{mV}$ ) is processed. However, many standard application work with significantly higher levels (typically more than 500 $\mathrm{mV}$ ). The very simple way of usage of OTA-based adjustable resistance exists as discussed [2]. The IC design offers promising features when appropriate linearization method can be applied. However, the commercial availability of these devices (OTAs using differential pair) is very limited (two or three active products) and they suffer from bandwidth or linearity issues.

We tested five types of easily available electronically (voltage) adjustable equivalent of resistance operating in dynamics of units-tens of $\mathrm{mA}$ and frequency bandwidths in hundreds and units of MHz. These circuits can be used in various applications based on operational amplifiers and other active elements effectively.

\section{REFERENCES}

[1] B. Razavi, Design of analog CMOS integrated circuits, $2^{\text {nd }}$ ed., New York, McGraw-Hill, 2016, 800 pages.

[2] R. L. Geiger and E. Sánchez-Sinencio, "Active filter design using operational transconductance amplifiers: A tutorial," IEEE Circuits and Devices Magazine, vol. 1, no. 2, pp. 20-32, 1985.

[3] D. Biolek, R. Senani, V. Biolkova, Z. Kolka, "Active elements for analog signal processing: Classification, Review and New Proposals," Radioengineering, vol. 17, no. 4, pp. 15-32, 2008.

[4] R. Senani, D. R. Bhaskar, A. K. Singh, Current Conveyors: Variants, Applications and Hardware Implementations, Springer, Berlin, Germany, 2015.

[5] E. Lunca, C. Damian, D. Petrisor and O. Postolache, "Programmable active filters based on digital potentiometers," in Proc. International Conference and Exposition on Electrical and Power Engineering, Iasi, 2012, pp. 787-791.

[6] I. M. Pandiev, "Behavioral modeling of CMOS digital potentiometers using VHDL-AMS," in Proc. IEEE International Power Electronics and Motion Control Conference (PEMC), Varna, 2016, pp. 940-945.

[7] Maxim Integrated. DACs vs. Digital Potentiometers: Which Is Right for My Application? 2007, 1 p., accesssible on www: https://www.maximintegrated.com/en/app-notes/index.mvp/id/4025

[8] V. K. Mehta, R. Mehta, Principles of electronics, $1^{\text {st }}$ edition, New Delhi, India, S. Chand and Company, 1980, 792 pages.

[9] R. Senani, "Realization of a class of analog signal processing/signal generation circuits: Novel configurations using current feedback opamps," Frequenz, vol. 52, no. 9/10, pp. 196-206, 1998.

[10] D. R. Bhaskar and R. Senani, "New CFOA-Based Single-ElementControlled Sinusoidal Oscillators," IEEE Transactions on Instrumentation and Measurement, vol. 55, no. 6, pp. 2014-2021, 2006.

[11] J. Bajer, A. Lahiri, D. Biolek, "Current-mode CCII+ based oscillator circuits using a conventional and modified wien-bridge with all capacitors grounded," in Proc. International Conference on EDSIMAPS 2010, Brno, 2010, pp. 5-10.

[12] J. Bajer, A. Lahiri, D. Biolek, "Current-Mode CCII+ Based Oscillator Circuits using a Conventional and a Modified Wien-Bridge with All Capacitors Grounded," Radioengineering, vol. 20, no. 1, pp. 245-251, 2011.

[13] V. Biolkova, J. Bajer, D. Biolek, „Four-Phase Oscillators Employing Two Active Elements," Radioenginnering, vol. 20, no. 1, pp. 334-339. 2011.

[14] D. Biolek, A. Lahiri, W. Jaikla, M. Siripruchyanun, J. Bajer, „Realization of electronically tunable voltage-mode/current-mode 
quadrature sinusoidal oscillator using ZC-CG-CDBA," Microelectronics Journal, vol. 42, no. 10, pp. 1116-1123, 2011.

[15] Luna Optoelectronics. NSL-32SR3 Optocoupler (datasheet), 2016, 2 p., accesible on: http://lunainc.com/wp-content/uploads/2016/06/NSL32SR3.pdf

[16] R. Sotner, J. Jerabek, L. Langhammer, J. Dvorak, "Design and Analysis of CCII-Based Oscillator with Amplitude Stabilization Employing Optocouplers for Linear Voltage Control of the Output Frequency," Electronics, vol. 7, no. 9(157), pp. 1-20, 2018.

[17] R. Sotner, A. Kartci, J. Jerabek, N. Herencsar, T. Dostal, K. Vrba, “An Additional Approach to Model Current Followers and Amplifiers with Electronically Controllable Parameters from Commercially Available ICs," Measurement Science Review, vol. 12, no. 6, pp. 255-265, 2012.

[18] R. Sotner, N. Herencsar, J. Jerabek, L. Langhammer, J. Polak, "On practical construction of electronically controllable compact current amplifier based on commercially available elements and its application," AEU - International Journal of Electronics and Communications, vol. 81, no. 11, pp. 56-66, 2017.

[19] R. Sotner, L. Langhammer, J. Petrzela, O. Domansky and T. Dostal, "Applications of novel behavioral implementation of a controllable generalized current conveyor," in Proc. 28th International Conference Radioelektronika, Prague, 2018, pp. 1-6.

[20] Texas Instruments. VCA822 Wideband, $>40-\mathrm{dB}$ Gain Adjust Range, Linear in V/V Variable Gain Amplifier, 2015, 48 p., accessible on www: http://www.ti.com/lit/ds/symlink/vca822.pdf

[21] Texas Instruments. VCA824 Ultra-Wideband, > 40-dB Gain Adjust Range, Linear in V/V Variable Gain Amplifier, 2019, 42 p., accesssible on www: http://www.ti.com/lit/ds/sbos394e/sbos394e.pdf

[22] Texas Instruments. VCA810 High Gain Adjust Range, Wideband and Variable Gain Amplifier (datasheet), 2015, 41 p., accessible on www: http://www.ti.com/lit/ds/symlink/vca810.pdf

[23] Analog Devices. AD835 $250 \mathrm{MHz}$, Voltage Output, 4-Quadrant Multiplier (datasheet), 2014, 15 p., accessible on www: http://www.analog.com/media/en/technical-documentation/datasheets/AD835.pdf

[24] ON Semiconductor. JFET VHF/UHF Amplifiers (datasheet), 2001, 8 p., accessible on ww: https://www.onsemi.com/pub/Collateral/BF245A-D.PDF

[25] R. Raut, M. N. S. Swamy, Modern Analog Filter Analysis and Design: A practical approach. Weinheim, Germany: Willey-VCH Verlag $\mathrm{GmbH}$ and Co. KGaA, 2010. 